\title{
CO-EXISTING PYROXENES IN IGNEOUS AND METAMORPHIC ROCKS
}

SIR,-In recent issues of this magazine several papers have been published, dealing with co-existing pyroxenes in igneous and metamorphic rocks. The authors of these papers were concerned with the possibility of using the pyroxene tie-lines as a geological thermometer. It may be useful to consider the theoretical aspects of this problem.

The chemical equilibrium between calcium-rich and calcium-poor pyroxenes may be written as follows :

$$
\mathrm{CaFeSi}_{2} \mathrm{O}_{6}+\mathrm{MgSiO}_{3} \rightleftharpoons \mathrm{CaMgSi}_{2} \mathrm{O}_{6}+\mathrm{FeSiO}_{3}
$$

the condition of equilibrium being if the minerals are ideal solutions

$$
\left(\frac{\mathrm{Fe}^{++}}{\mathrm{Mg}}\right)_{\text {Ca-poor }}=\left(\frac{\mathrm{Fe}^{++}}{\mathrm{Mg}}\right)_{\text {Carich }} \times \mathrm{K}(\mathrm{T}) .
$$

Using the chemical analyses of co-existing pyroxenes found in the literature, one finds that the $\mathrm{K}$ value calculated from equation (1) is on the average 1.8 for metamorphic rocks (Mueller, 1960), 1.4 for igneous rocks, and 1.2 for olivine nodules. Since $\mathrm{K}$ is known to within a standard relative deviation of about 10 per cent the conclusion is reached that the pyroxene associations in rocks constitute a rather insensitive geological thermometer.

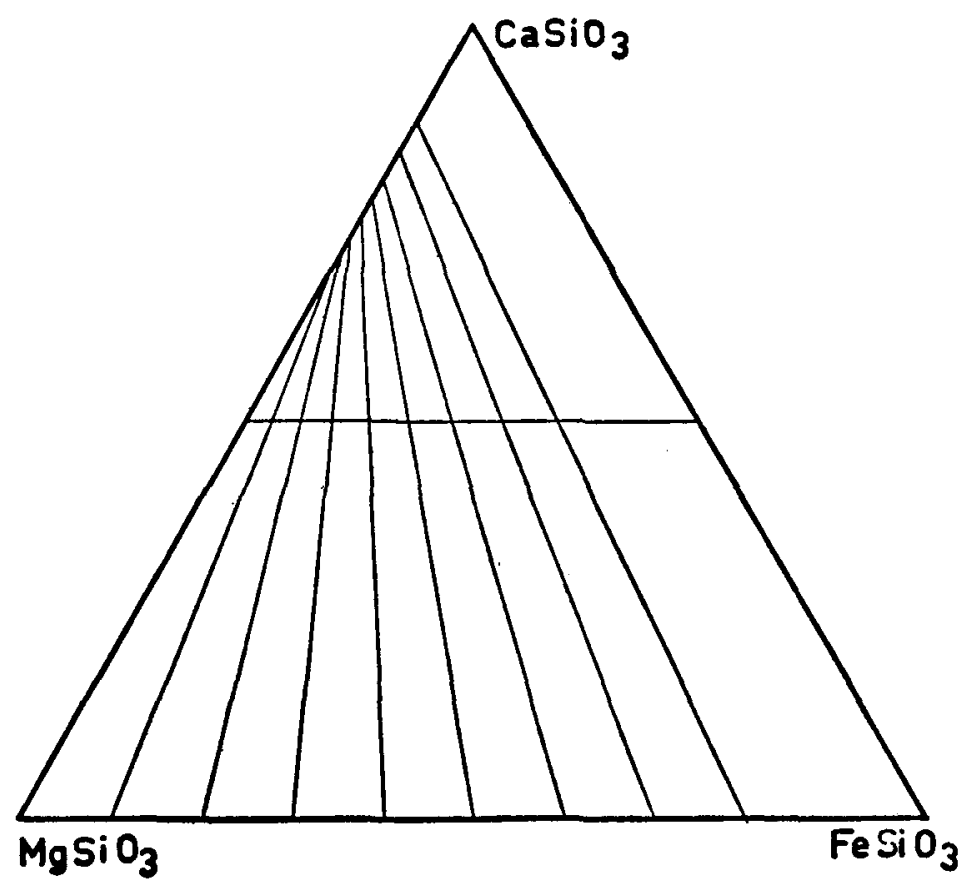

TEXT-FIG. 1.-The pyroxene equilibrium diagram based on the hypothesis that equation (1) is verified. Isothermal section drawn for $K=1.8$ and corresponding approximately to metamorphic conditions. 


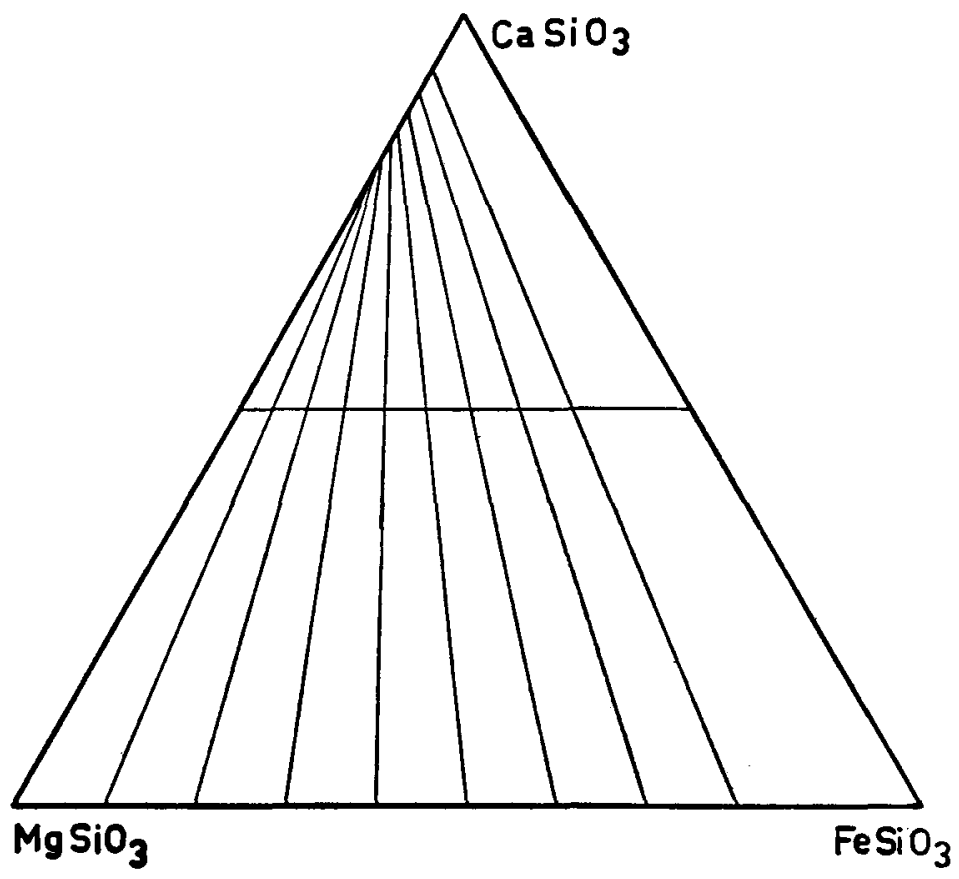

TeXT-FIG. 2.-Isothermal section drawn for $\mathrm{K}=1.4$ and corresponding approximately to igneous conditions.

Equation (1), which is approximately obeyed in natural systems, is represented graphically in Text-figs. 1 and 2 . These diagrams, corresponding to $\mathrm{K}$-values of 1.8 and 1.4 respectively, show what little difference should be expected between igneous and metamorphic tie-lines. It should be noted that, in Text-figs. 1 and 2, tie-lines are drawn between two points, one of which lies on the enstatite-ferrosilite join, and the other on the diopside-hedenbergite join ; in other words, consideration is given only to the iron-magnesium ratio in the minerals involved, the calcium content being disregarded.

Another conclusion emerges from an examination of Text-figs. 1 and 2 : the point where a tie-line intersects the left-hand side of the triangle cannot be expected to be a measure of temperature. Actually, tie-lines corresponding to the same temperature, i.e. belonging to the same isothermal section of the equilibrium diagram, do not meet at a point on the left-hand side of the triangle; they intersect outside the triangle. Such a conclusion may seem to contradict the facts observed since, in diagrams representing natural occurrences, tie-lines sometimes intersect within the triangle. The contradiction is, however, only apparent. Diagrams representing natural occurrences cannot be directly compared with Text-figs. 1 and 2 because in such diagrams (1) tie-lines in the magnesium-rich region correspond to a temperature somewhat higher than tie-lines in the iron-rich region ; (2) mineral compositions are plotted with due regard to the calcium content. In addition it should be observed that the upper part of a tie-line is very sensitive to any error in the determined composition of the calcium-rich pyroxene. 
May I finally add that, in the study of mineralogical equilibria, the practice of adding ferric iron and manganese to ferrous iron has no justification and can only bring confusion?

I am indebted to Dr. G. M. Brown for a stimulating discussion on pyroxene tie-lines.

\author{
UNIVERSTTÉ LOVANIUM, \\ LÉOPOLDVILLE, \\ RÉPUBLIQUE DU CONGO. \\ 13th February, 1961.
}

Paul Bartholomé.

\title{
REFERENCE
}

Mueller, R. F., 1960. Compositional characteristics and equilibrium relations in mineral assemblages of a metamorphosed iron formation. Amer. J. Sci., 258, 449-497.

\section{TERTIARY OF BARBADOS, W. I.}

SIR,- - In a recent paper on exploration results in Barbados, P. $\mathbf{H}$. Baadsgaard (1960) introduced several insufficiently defined stratigraphic terms that appear to offer no improvement on the definitions of A. Senn $(1940,1948)$.

Scotland Formation. Senn's Lower Scotland Formation includes the Morgan Lewis and the Walkers beds. Baadsgaard places his "P-unit" below the Walkers beds, and suggests the term "River Formation" for the three members. He describes his "P-unit" as " a new subsurface unit of black, sometimes fossiliferous silty shales and mudstones with few thin fine sandstones". Senn (1940, p. 1553) gave a thickness of 240 metres for the exposed type-section of the Walkers beds. In a bore-hole 650 metres of these beds were penetrated without having reached the bottom. The "P-unit" appears to form part of the lower, unexposed Walkers beds, hence the term "River Formation" appears to be unnecessary. If Baadsgaard wants to introduce a new subdivision he should bring out the lithological and palaeontological differences, and discuss the boundaries as seen in the Friendship well.

Senn's Upper Scotland Formation consists of Mount All, Chalky Mount, and Murphys beds. The "Bruce Vale Formation" of Baadsgaard embraces the same three members, and for this reason appears to be synonymous with Senn's Upper Scotland Formation.

Baadsgaard's "T-unit" is " a new subsurface stratigraphic element beneath the superficial Oceanic section in Friendship-1, Springvale-1, and Ince-1 ". This unit " consists of blue or purple claystones with thin siltstones and, locally, bedded sandstones and septarian limestones". In Text-fig. 2 the "T-unit" crosses the time lines from Middle Eocene to Upper Oligocene analogous to the older "P-unit". The "T-unit" of bore-hole Ince-1 is covered by beds of Baadsgaard's "Oceanic Group ", for which no age is given. Baadsgaard shows in his Text-fig. 3 at least " three superimposed major structural plates" which he assumes to be "sheet-like displacements with extensive overturned sections ". In none of the seven exploration wells is the "T-unit " involved in these tectonic complexities. It always rests on top of Senn's Scotland Formation, and below Baadsgaard's "Oceanic Group". Where palaeontologically identified in Ince-1, the "T-unit", Bruce Vale and River formations yielded faunas compared by Bronnimann with the Herrera member of the Cipero Formation of Trinidad. This makes them not older than Aquitanian and not "good Oligocene" as stated by Baardsgaard. Oceanic type marls are known from lower horizons of the Miocene, from Oligocene and from Eocene below which follows the Scotland Formation. Unless Baadsgaard can give strong proof of the highly diachronous nature of all these units it seems wiser to consider the younger, Miocene parts of the 